\title{
PENGARUH HUMAN RELATION, KONDISI FISIK LINGKUNGAN DAN ORGANIZATION BASED SELF-ESTEEM TERHADAP ETOS KERJA SERTA DAMPAKNYA PADA KINERJA KARYAWAN BPR KEDUNG ARTO SEMARANG
}

\author{
Iik Suryati Azizah \\ Program Studi Ketatalaksanaan Pelayaran Niaga dan Kepelabuhan Politeknik Bumi Akpelni \\ Jl. Pawiyatan Luhut II/17 Bendan Dhuwur Semarang \\ iik_suryati@yahoo.com
}

\begin{abstract}
This research intent to test Subjective implement effectiveness Human Relation, Condition of Environment Physical, Organization Based Self Esteem to job and Performance Ethos. Base former observational result, condition of environment physical constitute molded environment of implemented subjective human squire. Relationship among human contain mean a communication since its character that orientation on behavioral. Therefore, organization righteously has give freedom to fire an employee to get that communication they can collaborate properly in their work.

This research is done on BPR Kedung Arto at Semarang. Method that is utilized as method of census via pervading questionnaire of population a number 102 person. Two phase regression analysis is utilized as quantitative analysis.

Coefficients arithmetic result determinant totaled point out that $72 \%$ changing variable dependent can be worded by independent variables. Meanwhile its rest as big as $28 \%$ worded by outdoor other variables model observational. Hypthothesis testing result partially of each step points out to mark sense influence positively and significant of job Ethos to Performance. Hereafter, Human Relation, Condition of Environment Physical and OBSE each have influence positively and significant to job Ethos.
\end{abstract}

Keyword : Human Relation, Condition of Environment Physical, Organization Based Self Esteem, Job ethos, Performanc

\section{PENDAHULUAN}

BPR Kedung Arto adalah salah satu bank perkreditan rakyat yang mengemban amanat untuk membantu dan mendorong pertumbuhan ekonomi daerah melalui layanan jasa perbankan guna meningkatkan taraf hidup masyarakat kecil dan menengah di Wilayah Provinsi Jawa Tengah pada umumnya dan di wilayah kerja kantor Bank Indonesia Semarang pada khususnya

Dalam perkembangan selama tiga tahun terakhir, tampak adanya peningkatan turnover karyawan di BPR Kedung Arto seperti yang tampak pada tabel berikut ini:

Tabel 1 : Turnover Karyawan BPR Kedung Arto Semarang

\begin{tabular}{|c|c|c|c|c|}
\hline $\begin{array}{c}\text { N } \\
\mathbf{0}\end{array}$ & $\begin{array}{c}\text { Tah } \\
\text { un }\end{array}$ & $\begin{array}{c}\text { Karya } \\
\text { wan } \\
\text { Keluar }\end{array}$ & $\begin{array}{c}\text { Total } \\
\text { Jumlah } \\
\text { Karya } \\
\text { wan }\end{array}$ & $\begin{array}{c}\text { Persenta } \\
\text { se } \\
\text { Turnover } \\
(\%)\end{array}$ \\
\hline 1 & 2010 & 12 & 95 & 12,6 \\
\hline 2 & 2011 & 15 & 98 & 15,3 \\
\hline 3 & 2012 & 24 & 102 & 23,5 \\
\hline
\end{tabular}

Sumber: Bag. SDM BPR Kedung Arto Semarang, 2013
Peningkatan kinerja merupakan hal yang mutlak dilakukan oleh manajemen BPR mencapai tujuan BPR dan menjaga kelangsungan hidup serta mempertahankan eksistensi BPR dalam persaingan bisnis yang ketat sekarang ini. Peneliti merasa terdorong untuk melakukan penelitian yang bertujuan untuk mengetahui seberapa besar pengaruh human relation, kondisi fisik lingkungan dan OBSE terhadap etos kerja dan kinerja karyawan.

Berdasarkan latar belakang masalah yang telah diungkapkan diatas, maka masih diperlukan penelitian selanjutnya yang mengkaji tentang pengaruh hubungan antar manusia (human relation), kondisi fisik lingkungan kerja terhadap etos kerja dan kinerja pada BPR. Adapun alasan memilih objek studi tersebut dikarenakan sebelumnya penelitian mengenai faktor perilaku organisasi untuk karyawan di BPR masih relatif jarang dilakukan. Disamping itu, penelitian berikutnya dilakukan dengan mengacu pada bagaimana hubungan antar manusia khususnya antar karyawan BPR Kedung Arto berkaitan dengan kondisi fisik 
lingkungan yang ada sekarang ini dan Organization Based Self Esteem (OBSE) serta dampaknya terhadap etos kerja dan kinerja karyawan di dalamnya.

Dari semua uraian diatas maka dapat disusun beberapa pertanyaan penelitian sebagai berikut:

1. Apakah human relation (hubungan antar manusia) berpengaruh terhadap etos kerja?

2. Apakah kondisi fisik lingkungan berpengaruh terhadap etos kerja ?

3. Apakah Organization Based Self Esteem (OBSE) berpengaruh terhadap etos kerja?

4. Apakah etos kerja berpengaruh terhadap kinerja karyawan?

\section{TINJAUAN PUSTAKA}

\begin{tabular}{|l|l|}
\hline \multicolumn{1}{|c|}{ Variabel } & \multicolumn{1}{c|}{ Keterangan } \\
\hline Ruman & Human relation merupakan \\
& unsur dalam manajemen \\
& sumberdaya manusia yang \\
& menciptakan suatu \\
& komunikasi diantara sesama \\
& manusia dan hal ini akan \\
& dapat menimbulkan suatu \\
& sikap, pendapat atau perilaku \\
& yang saling pengertian \\
& didalam melaksanakan \\
& pekerjaan.(Jalaluddin, 1999) \\
\hline
\end{tabular}

\begin{tabular}{|l|l|}
\hline Kondisi Fisik & lingkungan kerja adalah \\
segala sesuatu yang ada \\
disekitar \\
pekerja dan dapat \\
mempengaruhi dirinya dalam \\
menjalankan tugas-tugas \\
yang dibebankan. \\
Nitisemito (1996)
\end{tabular}

\section{KERANGKA KONSEP PENELITIAN}
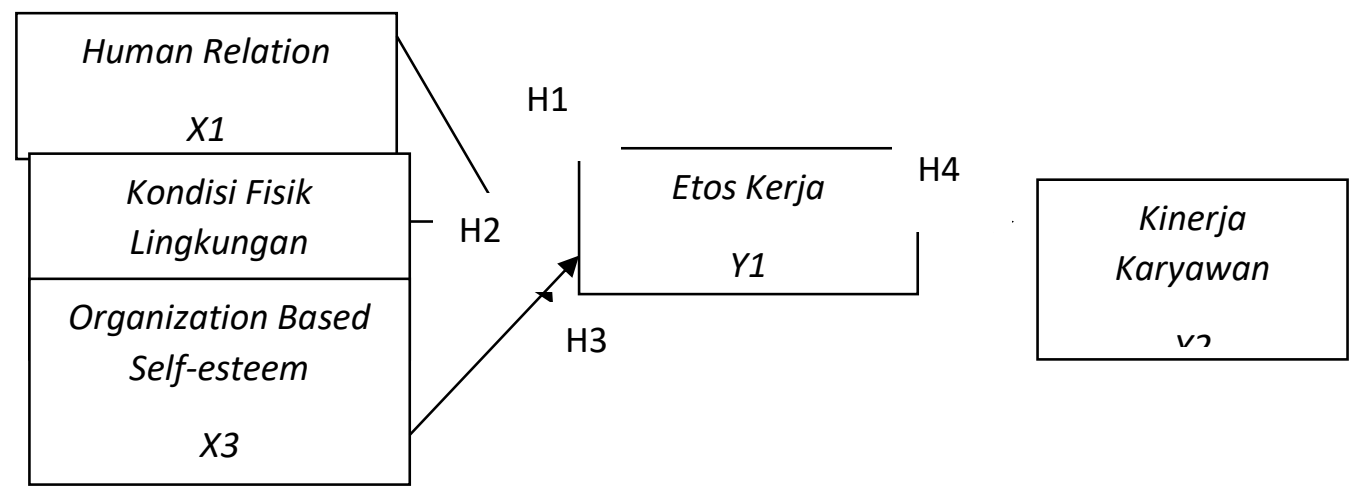

Gambar 1 : Kerangka Konsep Penelitian

\section{METODE PENELITIAN}

Penelitian ini menggunakan pendekatan kuantitatif. Pendekatan kuantitatif yang digunakan dalam penelitian ini adalah dengan menggunakan metode survei.
Metode pengumpulan data yang digunakan dalam penelitian ini adalah menggunakan kuesioner secara personal. Kuesioner secara personal digunakan untuk mendapatkan data tentang dimensi-dimensi 
dari konstruk-konstruk yang sedang dikembangkan dalam penelitian ini.

Populasi dalam penelitian ini adalah seluruh karyawan kantor pusat BPR Kedung Arto Semarang yang berjumlah 102 orang. Untuk mendapatkan hasil penelitian yang representatif, maka penelitian ini menggunakan seluruh responden sebagai subjek penelitian atau lebih dikenal dengan metode sensus.

\section{HASIL DAN PEMBAHASAN}

BPR kedung Arto didirikan pada tahun 1991 berdasarkan keputusan Menteri Keuangan Republik Indonesia No. Kep. 193/KM.13/1991 tanggal 15 Juli 1991 berkedudukan di Tengaran, Kabupaten Semarang yang mulai beroperasi pada tanggal 14 September 1991 dengan modal dasar dan modal disetor sebesar Rp. 750 Juta.

Berdasarkan pemikiran untuk lebih mendekatkan kepada nasabah dan pusat kegiatan perekonomian yang dibiayai, pada tanggal 3 September 1994, kantor pusat BPR Kedung Arto dipindahkan dari Jl. Raya Semarang - Solo Km. 58 Tengaran, Ke Jl. Raya Suruh No. 23 Kabupaten Semarang.

Dalam perkembangannya, BPR Kedung Arto mengalami kemajuan yang cukup pesat, sehingga perlu membuka kantor cabang di kota Semarang pada tanggal 2 Januari 2001, dengan didukung peningkatan modal dasar menjadi Rp. 1,5 Milyar.

Untuk lebih memantapkan kinerja BPR Kedung Arto sesuai dengan visi, misi dan tujuannya, pada tanggal 16 April 2001 Kantor Pusat BPR Kedung Arto dipindahkan ke Semarang dengan alamat Jl. Pandanaran No. 58 dan kantor di Suruh berubah statusnya menjadi kantor cabang. Setelah 4 tahun berkantor pusat di Semarang BPR Kedung Arto mengalami kemajuan yang sangat pesat sekali, dan untuk lebih mendukung perkembangannya, kantor pusatnya dipindahkan ke Jl. MT. Haryono No. 811 Semarang.

Analisis Regresi Parsial (Tahap Pertama) Model Summary ${ }^{b}$

\begin{tabular}{|c|c|c|c|c|c|c|c|c|c|}
\hline \multirow[b]{2}{*}{$\begin{array}{l}\text { Mo } \\
\text { del }\end{array}$} & \multirow[b]{2}{*}{$\mathrm{R}$} & \multirow[b]{2}{*}{$\begin{array}{c}\mathrm{R} \\
\text { Square }\end{array}$} & \multirow[b]{2}{*}{$\begin{array}{l}\text { Adjusted } \\
\text { R Square }\end{array}$} & \multirow[b]{2}{*}{$\begin{array}{l}\text { Std. Error } \\
\text { of the } \\
\text { Estimate }\end{array}$} & \multicolumn{5}{|c|}{ Change Statistics } \\
\hline & & & & & $\begin{array}{c}\text { R Square } \\
\text { Change }\end{array}$ & $\begin{array}{c}\mathrm{F} \\
\text { Chang } \\
\mathrm{e}\end{array}$ & df1 & df2 & $\begin{array}{c}\text { Sig. F } \\
\text { Change }\end{array}$ \\
\hline 1 & $.854^{\mathrm{a}}$ & .729 & .720 & 2.075 & .729 & 87.767 & 3 & 98 & .000 \\
\hline
\end{tabular}

a. Predictors: (Constant), OBSE, Lingkungan, HuRel

b. Dependent Variable: Etos

ANOVA $^{\mathrm{b}}$

\begin{tabular}{|ll|r|r|r|r|r|}
\hline \multicolumn{1}{|l|}{ Model } & Sum of Squares & \multicolumn{1}{c|}{ df } & Mean Square & F & Sig. \\
\hline 1 & Regression & 1133.919 & 3 & 377.973 & 87.767 & $.000^{\mathrm{a}}$ \\
& Residual & 422.042 & 98 & 4.307 & & \\
& Total & 1555.961 & 101 & & & \\
\hline
\end{tabular}


Model Summary ${ }^{b}$

\begin{tabular}{|c|c|c|c|c|c|c|c|c|c|}
\hline \multirow[b]{2}{*}{$\begin{array}{l}\text { Mo } \\
\text { del }\end{array}$} & \multirow[b]{2}{*}{$\mathrm{R}$} & \multirow[b]{2}{*}{$\begin{array}{c}\mathrm{R} \\
\text { Square }\end{array}$} & \multirow[b]{2}{*}{$\begin{array}{l}\text { Adjusted } \\
\text { R Square }\end{array}$} & \multirow[b]{2}{*}{$\begin{array}{l}\text { Std. Error } \\
\text { of the } \\
\text { Estimate }\end{array}$} & \multicolumn{5}{|c|}{ Change Statistics } \\
\hline & & & & & $\begin{array}{l}\text { R Square } \\
\text { Change }\end{array}$ & $\begin{array}{c}\text { F } \\
\text { Chang } \\
\text { e }\end{array}$ & df1 & df 2 & $\begin{array}{c}\text { Sig. F } \\
\text { Change }\end{array}$ \\
\hline 1 & $.854^{\mathrm{a}}$ & .729 & .720 & 2.075 & .729 & 87.767 & 3 & 98 & .000 \\
\hline
\end{tabular}

a. Predictors: (Constant), OBSE, Lingkungan, HuRel

b. Dependent Variable: Etos

Coefficients $^{\mathrm{a}}$

\begin{tabular}{|c|c|c|c|c|c|c|}
\hline \multirow{2}{*}{\multicolumn{2}{|c|}{ Model }} & \multicolumn{2}{|c|}{ Unstandardized Coefficients } & \multirow{2}{*}{$\begin{array}{c}\text { Standardized } \\
\text { Coefficients }\end{array}$} & \multirow[b]{2}{*}{$\mathrm{t}$} & \multirow[b]{2}{*}{ Sig. } \\
\hline & & B & Std. Error & & & \\
\hline \multirow[t]{4}{*}{1} & (Constant) & .232 & .822 & & .282 & .778 \\
\hline & HuRel & .318 & .135 & .262 & 2.361 & .020 \\
\hline & Lingkungan & .278 & .080 & .384 & 3.473 & .001 \\
\hline & OBSE & .159 & .068 & .255 & 2.351 & .021 \\
\hline
\end{tabular}

a. Dependent Variable: Etos

Analisis Regresi Parsial Kedua (Tahap Kedua)

Coefficients $^{\mathbf{a}}$

\begin{tabular}{|c|c|c|c|c|c|c|}
\hline \multirow{2}{*}{\multicolumn{2}{|c|}{ Model }} & \multicolumn{2}{|c|}{$\begin{array}{l}\text { Unstandardized } \\
\text { Coefficients }\end{array}$} & \multirow{2}{*}{$\begin{array}{c}\text { Standardized } \\
\text { Coefficients } \\
\text { Beta }\end{array}$} & \multirow[b]{2}{*}{$\mathrm{t}$} & \multirow[b]{2}{*}{ Sig. } \\
\hline & & $\mathrm{B}$ & Std. Error & & & \\
\hline 1 & (Constant) & 8.974 & 1.472 & & 6.095 & .000 \\
\hline & Etos & .746 & .111 & .558 & 6.727 & .000 \\
\hline
\end{tabular}

Koefisien Korelasi dan Regresi Ganda

Model Summary ${ }^{b}$

\begin{tabular}{|l|c|r|r|r|}
\hline Model & R & R Square & $\begin{array}{c}\text { Adjusted R } \\
\text { Square }\end{array}$ & $\begin{array}{c}\text { Std. Error of } \\
\text { the Estimate }\end{array}$ \\
\hline 1 & $.854^{\mathrm{a}}$ & .729 & .720 & 2.075 \\
\hline
\end{tabular}

a. Predictors: (Constant), OBSE, Lingkungan, HuRel

b. Dependent Variable: Etos 
Hasil penelitian menunjukkan bahwa variabel etos kerja berpengaruh secara kuat terhadap kinerja karyawan. Hal tersebut menunjukkan bahwa kinerja karyawan akan dapat ditingkatkan dengan memaksimalkan etos kerja karyawan. Jika etos kerja meningkat, maka berakibat langsung dengan peningkat kinerja karyawan. Sebaliknya jika etos kerja menurun, maka kinerja karyawan tidak dapat ditingkatkan. Dalam penelitian ini ditemukan juga fakta empiris yang membuktikan pengaruh human relation, kondisi fisik lingkungan dan OBSE terhadap etos kerja. Upaya manajemen dalam meningkatkan etos kerja dapat dilakukan dengan cara memberikan aturan yang jelas dan tegas kepada karyawan, misal dengan memberikan reward dan punishment, memberikan prosedur secara jelas pada masing-masing pekerjaan karyawan serta adanya rambu-rambu yang dapat dijadikan sebagai pedoman dalam bertingkah laku sehari-hari sebagai karyawan.

Organisation-Based Self-Esteem

(OBSE) karyawan dapat ditingkatkan misalnya dengan kepedulian pada kepentingan, persoalan, status dan kontribusi setiap anggota organisasi, ikatan yang didasari kepercayaan antara rekan kerja dan atasan, serta penghargaan yang tulus pada setiap keberhasilan individu dalam organisasi.

Karena Etos Kerja juga dipengaruhi oleh faktor agama, organisasi perlu memperhatikan dan mendukung kegiatankegiatan keagamaan yang dapat menghimpun para karyawan, meskipun hal ini bukan menjadi bagian utama dalam agenda kerja organisasi, memelihara pemahaman nilai-nilai agama dapat membentuk Etos Kerja.

Struktur ekonomi juga merupakan faktor pendorong Etos Kerja. Gardner, Dyne, \& Pierce (2004) menemukan bahwa tingkatan gaji turut mempengaruhi rasa berharga seorang individu sebagai anggota organisasi, sehingga organisasi perlu mempertimbangkan sistem penggajian berbasis kompetensi agar balas jasa yang diperoleh karyawan sesuai dengan kualitas kerja yang diharapkan darinya serta dapat memenuhi rasa keadilan.

\section{KESIMPULAN DAN SARAN}

Guna meningkatkan etos kerja dan meningkatkan kinerja karyawan, yaitu dengan:
1. Meningkatkan keakraban dan kerja sama antar karyawan dengan rutin mengadakan gathering, pertemuan informal sehingga kesepahaman dalam menjalankan pekerjaan dapat ditingkatkan. Pendekatan pimpinan terhadap karyawan hendaknya dilakukan dengan suasana yang lebih santai, sehingga maksud yang ingin disampaikan dapat lebih ditangkap oleh karyawan dengan baik.

2. Kondisi fisik lingkungan BPR Kedung Arto perlu ditingkatkan lebih baik, seperti halnya dengan penataan ruang yang lebih aksesibel dan pengecatan yang hangat, sehingga dalam bekerja tidak terlalu dibebani dengan suasana yang mencekam.

3. Guna meningkatkan self esteem karyawan dapat dilakukan dengan memberikan keleluasaan pada karyawan untuk meningkatkan kompetensi yang dimiliki serta diikutsertakan dalam pengambilan keputusan berkaitan dengan kebijakan di BPR Kedung Arto Semarang

4. Guna mewujudkan bobot atau kualitas dalam penelitian ini, maka diharapkan pada penelitian mendatang:

a. Menggunakan objek penelitian yang lebih luas, misal seluruh BPR di Jawa Tengah.

b. Menggunakan variabel di luar penelitian yang berpengaruh terhadap kinerja karyawan, meliputi motivasi, kecerdasan emosional, dan sebagainya.

\section{DAFTAR PUSTAKA}

Alex Nitisemito. 1996. Manajemen Personalia ( Manajemen Sumber Daya Manusia ). Kudus: Ghalia Indonesia. 
Anoraga, Drs. Pandji. (1992); Psikologi Kerja; PT. Rineka Cipta, Jakarta.

Cascio, Wayne F. (2003); Managing Human Resource; Productivity, Quality of Work Life, Profits (6th ed.); McGraw Hill/Irwin, New York.

Chaplin, J.P. 2001. Kamus Psikologi. ( Terjemahan: Kartono, K ). Bandung: CV. Pionir Jaya.

Davis, Keith. 1989. Human Behaviour At Work, 8th ed. Singapore: McGrawHill,Inc.

Deaux, Kay.; Dane, Francis C.; Wrightsman, Lawrence S. (1993); Social Psychology in the 90's (6th Ed); Brooks/Cole Publishing Company, California.

Dessler, Gary. 2007. Manajemen Sumber Daya Manusia. Edisi 10. Jakarta: PT. Indeks.

Donald G. Gardner, Linn Van Dyne, and Jon L. Pierce (2004); The effects of pay level on organization-based selfesteem and performance: A field study; Journal of Occupational and Organizational Psychology, 77, 307322

Emory C. William dan Donald R. Cooper. 1995. Businnes Research Methods, Boston.

Gibson, J.L dan Ivancevich, John M. 1994. Organisasi, Struktur dan Manajemen. ( Terjemahan: Djoerban Wahid, S.H ). Jakarta: Erlangga.

Gozali, Imam, 2005, Aplikasi Analisis Multivariate dengan Program SPSS, Badan Penerbit Universitas Diponegoro.

Greenberg, J. (2005). Managing behavior in organizations, Prentice Hall, USA

Hani Handoko. ( 1993 - 2001 ). Manajemen Personalia dan Sumber Daya Manusia. Yogyakarta: BPFEYogyakarta.

Hogg, Michael A.; Vaughan, Graham M. (2002); Social Psychology (3rd ed); Prentice Hall Pearson education limited, Edinburgh.

Hornby, A S., (1995); Oxford Advanced Learners Dictionary of Current English(5th ed.); Oxford University Press, Great Britain.

Ibnu Widiyanto. 2008. Pointers Metodologi Penelitian. Semarang: CV. Dikalia.
Iga Manuati Dewi. 2002. Makalah. Mengapa dan Untuk Apa Orang Bekerja?. Bali: Universitas Udayana.

Imam Ghozali. 2001. Ekonometrika: Teori Dan Aplikasi Dengan SPSS.

Ivancevich, John M., Konopaske, Robe 81 Michael T. Matteson. 2007. Peimanu dan Manajemen Organisasi. Ed.7. Jakarta: Erlangga.

Jalaluddin Rakhmad. 1999. Psikologi Komunikasi. Jakarta.

Jansen Sinamo. 2005. 8 Etos Kerja Profesional. Jakarta: PT. Spirit Mahardika.

Kernis, Michael H., (1995); Efficacy, Agency, and Self Esteem; Plenum Press, New York, and London.

Kreitner, Robert.; Kinicki, Angelo., (2000); Organizational behavior (8th Ed); McGraw Hill, New York.

Kusnan, Ahmad (2004); Analisis Sikap Iklim Organisasi, Etos Kerja Dan Disiplin Kerja Dalam Menentukan Efektifitas Kinerja Organisasi di Garnizun Tetap III Surabaya; Laporan Penelitian; http://www.damandiri.or.id/ index.php

Lee, Cynthia., Hui, Chun., (2000), Moderating Effects of OrganizationBased Self-esteem on Organizational Uncertainty: Employee Response Relationships; Journal of Management, Vol. 26, No. 2, 215232 Southern Management Association; http://jom.sagepub.com

Liliweri Alo. 1997. Komunikasi Antarprbadi. Jakarta: PT. Indeks.

Manullang, Marihot AMH. 1990. Manajeman Personalia. Cetakan Ketiga. Yogyakarta: Gadjah Mada University Press.

Mathis, Robert L. dan John H. Jackson. 2005. Human Resources Management: Manajemen Sumber Daya Manusia. Ed. 10. Jakarta: Salemba Empat.

McAllister, D.J. \& Gregory A. Bigley. 2002. Work Context And The Definition of Self: How Organizational Care Influences Organizational-Based Self-Esteem. The Academy of Management Journal, 45(5):894-913.

Mochtar Lubis. 1999. Manusia Indonesia. Jakarta. 
Nurhadi Subroto. 2005. Pengaruh Pelatihan, Motivasi dan Lingkungan Kerja Terhadap Kinerja Pegawai Dinas Peternakan dan Perikanan Kabupaten Semarang. Thesis Surakarta: Program Pascasarjana Magister Manajemen UMS.

Onong, Uchjana Effendy. ( 2001 - 2003 ). Ilmu, Teori dan Filsafat Komunikasi. Jakarta: Erlangga.

Ovi Setya Prabowo. 2008. Analisis Pengaruh Human Relation, Kondisi Fisik Lingkungan Kerja, dan Leadership Terhadap Etos Kerja Karyawan Kantor Pendapatan Daerah Di Pati. Skripsi Surakarta: Manajemen UMS.

Pierce, J.L.,D.G. Gardner, L.L. Cummings \& R.B. Dunham. 2003. OrganizationalBased Self-Esteem: Construct Definition, Measurement And Validation. The Academy of Management Journal, 32(3):622-648.

Purnomo Budi Setiyawan dan Waridin. 2006. Pengaruh Disiplin Kerja Karyawan dan Budaya Organisasi terhadap Kinerja di Divisi Radiologi RSUP Dokter Karyadi Semarang. Jurnal Riset Bisnis Indonesia Vol.2, No.2, Juli, hlm.181-198.

Reksohadiprojo dan Hani Handoko. 1997. Organisasi Perusahaan: Teori, Struktur dan Perilaku. Yogyakarta: BPFE-Yogyakarta.

Rivai, Vethzal. 2004. Performance Appraisal. Jakarta: PT. Rajagrafindo.

Rica Siahaan. 2007. Hubungan Etos kerja dan motivasi terhadap Kinerja pada PT Petrokimia Gresik. Thesis Universitas Brawijaya Malang.

Robbins, Stephen P. dan Timothi A. Judge. 2008. Perilaku Organisasi. Ed.12. Jakarta: Salemba Empat.

Robbins, Stephen. 2001. Organizational Behaviour: Concepts, Controversies, Aplications. $7^{\text {th }}$ Edition: Prentice Hall International, Inc.

Rosmiani, (1996); Etos Kerja Nelayan Muslim Di Desa Paluh Sebaji Deli Serdang Sumatera Utara; Hubungan Antara Kualitas Keagamaan dengan Etos Kerja; Thesis; Kerjasama Program Pascasarjana Institut Agama Islam Negeri Jakarta \& Pascasarjana UI Jakarta.
Sarwoto. 1991. Dasar-dasar Organisasi dan Manajemen. Jakarta: Ghalia Indonesia.

Siagian, Prof. Dr. Sondang P., (1995); Teori Motivasi Dan Aplikasinya; PT. Rineka Cipta, Jakarta

Sinamo, Jansen., (2005); Delapan Etos Kerja Profesional; Navigator Anda Menuju Sukses; Grafika Mardi Yuana, Bogor.

Soeprihanto, John. 2001. Penilaian Kinerja dan Pengembangan Karyawan Cetakan Kelima. Yogyakarta: BPFEYogyakarta.

Sunyoto Munandar Ashar. 2001. Psikologi Industri Dan Organisasi. Jakarta: Universitas Indonesia.

Tan Kim Sek (2003); Organizational Socializational Tactics And Organizational Based Self-esteem; Thesis Submitted In Fulfillment Of The Requirements For The Degree Of Doctor Of Philosophy.

Tang, Thomas Li-Ping; Gilbert, Pamela Rae. (1992); Organization-Based Self Esteem among Mental Health Workers: A Replication and Extension; Research Reports; http://eric.ed.gov/ERICWebPortal

Toto Tasmara. 2002. Etos Kerja Islami. Jakarta: Gema Insani Pres.

Weber, Max. (1958); The Protestant Ethic and the Spirit of Capitalism. Translated by Talcott Parsons. Charles Scribner's Sons, New York.

Wills, Mike., (1993); Managing The Training Process; putting the basic into practice; McGraw Hill, Great Britain 